\title{
Medicina de Família do Primeiro ao Sexto Ano da Graduação Médica: Considerações sobre uma Proposta Educacional de Integração Curricular Escola-Serviço Family Medicine from the First to the Final Year of Undergraduate Medical Training: Considerations about an Educational Proposal to Integrate Service-Learning into the Curriculum
}

\author{
Andréa Tenório Correia da Silva $a^{I, I}$ \\ Martim Elviro de Medeiros Junior ${ }^{1}$ \\ Paulo de Nogueira Fontão \\ Haraldo Cesar Saletti Filho \\ Pedro Félix Vital Junior \\ Monique Marie Marthe Bourget \\ Izabel Cristina Rios ${ }^{I, I I}$
}

\section{PALAVRAS-CHAVE}

- Educação Médica.

- Modelos Educacionais.

- Aprendizagem.

- Medicina de Família e Comunidade.

- Atenção Primária à Saúde.
REVISTA BRASILEIRA DE EDUCAÇÃO MÉDICA 


\section{KEYWORDS}

- MedicalEducation

- EducationalModels.

- Learning.

- FamilyPractice.

- PrimaryHealth Care.

Recebido em: 11/11/2016

Aprovado em: 18/11/2016
ABSTRACT

Medical education has been heavily debated in both national and international contexts due to changes in society and public health demands. In Brazil, it is postulated that learning in Primary Health Care (PHC) should occur throughout the entire medical course. Learning in PHC has faced some barriers such as inadequate environment for medical practice, including a lack of supervisors and general practitioners with insufficient training to assist students, lack of lecturers with expertise in the area, and resistance from traditional faculties to include PHC in the curriculum. This paper addresses an educational model to include PHC and family medicine in a medical school curriculum in the city of São Paulo, Brazil. Furthermore, we describe the challenges of tying in educational and managerial objectives in the context of primary care services, and how to overcome such challenges. Our proposal is based on using educational objectives to develop student competencies (knowledge, skills and attitudes) so they can provide comprehensive care as regards the individual's background (social, family and environmental). Students are exposed to increasingly complex educational content that requires connecting new knowledge to previous knowledge. The innovative aspect of this educational project is its integration of planning and educational management, involving the following strategies to achieve a better quality learning process: (1) Students in primary care services from the first to the last semester of the course; (2) Hiring family doctors as faculty members; (3) Integrating PHC and family medicine with the contents of other subjects such as epidemiology, public health policies and evidenced-based medicine; (4) Using problem-solving methodologies suitable both to the studied theme and to student and lecturer profiles; (5) Formative evaluations; (6) Improving teaching skills for lecturers and field supervisors; (7) Implementing practices to encourage students to work in multi-professional teams; (8) Motivating students to take part in interchange programs with national and international institutions; and (9) Encouraging the publications of books, scientific papers and research into PHC and family medicine. Several factors facilitate the success of this educational proposal, including: PHC and family medicine being underlying matters in the political-pedagogical faculty project; the educational setting being that of an institution with a long history of health education, public care provision and contributions to service-learning integration; the close relationship between health service managers, lecturers and supervisors, which facilitates coordination between the theoretical content and practice in PHC; the investments made to develop supervisor teaching skills, to support their participation in the debate about relevant family medicine content, and in the discussion about integrating theory with practice; and finally the human resource policies that raise the value of family doctors who are also supervisors. We hope this experience contributes to enhancing the debate about PHC and family medicine educational models in medical courses, and the related challenges and possibilities within medical training.

\section{INTRODUÇÃO}

Professor, para que ter posto de saúde e medicina de família do primeiro ao sexto ano? (estudante de graduação)

Qualquer especialista de hospital, que estudou coisas muito mais complexas, pode ser médico de família... (professor de Medicina)

Questões como estas, vindas de professores e alunos de Medicina, revelam um imaginário cultural sobre a Medicina de Família marcado por desconhecimento do campo e das propostas curriculares da Atenção Primária à Saúde (APS) e da Medicina de Família e Comunidade (MFC) na educação médica. Tradicionalmente centrada no hospital, a educação médica se encontra em revisão frente às mudanças na atenção e no ensino em saúde.
Nos últimos 40 anos, o Brasil passou por uma transição sociodemográfica e epidemiológica. A população cresceu de 94 milhões em 1970 para 191 milhões em 2010, e a expectativa de vida ao nascer aumentou de 52,3 anos em $1970^{1}$ para 75,2 anos em 2015. Novos problemas de saúde emergiram, como doenças crônicas e transtornos mentais ${ }^{2}$, constituindo desafios para o Sistema Único de Saúde (SUS). Diante desse cenário socioeconômico, demográfico e epidemiológico, as escolas médicas passaram a discutir o ensino superior em saúde frente às necessidades do contexto atual e a propor modificações para atender às demandas de saúde e cuidado.

Para o curso de Medicina, a proposta de modificação nesse sentido foi delineada nas Diretrizes Curriculares Nacionais (DCN) em 20013. Estas destacaram a necessidade de readequar os currículos de Medicina, buscando formar médicos com vi- 
são "humanista, crítica, reflexiva e ética", capaz de ofertar cuidado integral, longitudinal, identificando a determinação social do processo de saúde e doença ${ }^{3}$. Os ministérios da Saúde e da Educação criaram o Projeto de Incentivo a Mudanças Curriculares nas Escolas de Medicina (Promed) com o objetivo de estimular mudanças nos cursos médicos e promover adequação da formação profissional às necessidades do SUS ${ }^{4}$. Em 2014, a revisão das DCN reafirma a necessidade de adequar o ensino às demandas, destacando que:

os conteúdos fundamentais para o Curso de Graduação em Medicina devem estar relacionados com todo o processo saúde-doença do cidadão, da família e da comunidade [...], proporcionando a integralidade das ações do cuidar em saú$d e^{5} .(\mathrm{p} .10)$

Propondo, assim, um redesenho metodológico que insere cenários de prática na Atenção Primária para o desenvolvimento de tais conteúdos, inclusive no internato. As DCN 2014 defendem que no mínimo $30 \%$ da carga horária do internato sejam desenvolvidos na APS e em Serviço de Urgência/Emergência do SUS 5 .

As orientações das DCN para modificações dos currículos médicos, incluindo a ampliação da carga horária na APS, alinham-se à recomendação da Associação Brasileira de Ensino Médico (Abem) e da Sociedade Brasileira de Medicina de Família e Comunidade de inserir a APS no ensino médico, destacando a prática clínica integral, longitudinal, com orientação familiar e comunitária, tendo como cenário as Unidades Básicas de Saúde. Além disso, preconizam que a inserção da APS seja contínua durante todo o curso médico ${ }^{6}$.

Entre os anos de 2000 e 2015, observou-se um aumento significativo do número de cursos médicos no Brasil, principalmente de faculdades particulares, que atualmente correspondem a $60 \%$ do total. Em 2015, o número de escolas médicas alcançou a marca de 266 no País ${ }^{7}$. A cada ano, são formados mais de 24 mil médicos. A maioria das escolas mais antigas e muitas das recém-criadas têm currículos inspirados no modelo flexneriano(1910), apoiado nas Ciências Biológicas, Química e Física, e na formação prática em hospitais e laboratórios como principais cenários de ensino-aprendizagem ${ }^{8}$. $\mathrm{O}$ ensino médico nessas bases alçou qualidade científica, mas também resultou em centralidade biomédica que tangencia o processo saúde-doença no âmbito coletivo e familiar, com limitado alcance no que se refere ao contexto de vida e aos determinantes sociais do processo saúde-doença.

As dificuldades para implementar modificações curriculares para inserção de APS e MFC articulam-se a outros fatores, como resistência de docentes em implantar um novo modelo, docentes sem suficiente capacitação para o ensino na área e cenários práticos que não favorecem o processo educacional, como planta física inadequada das UBS, falta de preceptores e formação insuficiente dos médicos generalistas para receber estudantes ${ }^{9}$.

Nesse contexto, os cursos médicos no Brasil têm se adaptado de maneira heterogênea às modificações preconizadas pelas DCN. Na literatura nacional, encontramos poucos estudos que descrevem experiências de ensino-aprendizagem no cenário de $\mathrm{APS}^{10-12}$. Em particular, são escassas publicações científicas que descrevam e avaliem modelos de inserção da APS no currículo baseados em competências a serem desenvolvidas.

Diante de tais dificuldades e da proliferação de escolas médicas, é essencial compartilhar iniciativas de inserção curricular de MFC e APS, sua gestão educacional e articulação ensino-serviço. O presente artigo descreve e analisa um modelo de inserção da APS e MFC do primeiro ao último semestre no curso médico da Faculdade de Medicina Santa Marcelina (FASM), bem como apresenta os desafios enfrentados e as ações de articulação ensino-gestão realizadas para superá-los.

\section{O CONTEXTO LOCAL}

O Complexo de Saúde Santa Marcelina (CSSM) atua na região leste do município de São Paulo desde 1961, quando foi inaugurado o Hospital Santa Marcelina. Essa região tem 3.620.429 habitantes e é caracterizada por ser uma área de média a alta vulnerabilidade social ${ }^{13}$.

Atualmente, o CSSM administra três hospitais terciários no município de São Paulo (Itaquera, Itaim Paulista e Cidade Tiradentes) e gerencia 1.770 leitos, sendo 90 leitos de Unidades de Terapia Intensiva. O hospital de Itaquera realiza por ano, em média, 150 mil atendimentos no pronto-socorro, $400 \mathrm{mil}$ atendimentos ambulatoriais, 25 mil internações e 14 mil cirurgias. Em 1989, o Hospital Santa Marcelina recebeu credenciamento provisório para os programas de residência médica de Clínica Médica, Clínica Cirúrgica, Cirurgia Vascular, Ortopedia e Anestesiologia. Foi reconhecido oficialmente como hospital-escola em 2004 e hoje oferece 42 programas de residência médica credenciados pelo Ministério da Educação (MEC).

Além da atuação nos hospitais, o CSSM também atua em serviços de APS desde 1996, inicialmente por meio de parceria com o governo do Estado, no projeto Qualidade Integral em Saúde (Qualis), e atualmente,em parceria com a Secretaria Municipal de Saúde de São Paulo, no gerenciamento de 146 serviços de saúde, entre eles: Unidades Básicas de Saúde, centros de atenção psicossocial, equipes de atenção domiciliárias, 
ambulatórios médicos assistenciais e centros de reabilitação. As 196 equipes de saúde da família realizam cobertura de aproximadamente um milhão de pessoas nas regiões do Itaim Paulista, Itaquera, Cidade Tiradentes, Guaianases e São Miguel Paulista.

Em 2012, foi criada a Faculdade de Medicina Santa Marcelina, cujo modelo curricular propõe a inserção da MFC e da APS do primeiro ao último semestre do curso, integradas verticalmente (entre os módulos da MFC) e transversalmente com as demais disciplinas do semestre.

\section{O PROJETO POLÍTICO-PEDAGÓGICO}

O Projeto Político-Pedagógico da FASM, implantado em 2012, baseia-se no desenvolvimento de competências estabelecidas no perfil do egresso segundo as DCN do ensino médico definidas pelo Ministério da Educação em 2001 e ratificadas em 2014.

A formulação desse projeto ocorreu com base na experiência de ensino e de assistência do CSSM e na articulação com a Universidade de Toronto. O intercâmbio de alunos entre as duas instituições iniciou-se em 2014 com a vinda de residentes do terceiro ano de Medicina de Família (Global Health) para estágio de seis meses.

Como contribuição da parceria com a Universidade de Toronto, no currículo médico da FASM, foram reforçados cinco pontos-chave para a formação médica descritos pelo Colégio Canadense de Medicina de Família, aspectos centrais também propostos pelas DCN, tendo a MFC e a APS como fundamento axial de elaboração curricular: (1) capacidade de gerenciamento do caso clínico; (2) capacidade de trabalhar em equipe; (3) capacidade de comunicar-se adequadamente com pacientes, familiares e a equipe; (4) habilidade de praticar a medicina baseada em evidências; (5) desenvolvimento de ações para promover a saúde e o bem-estar do paciente e da comunidade.

\section{MFC E APS NO CURRÍCULO MÉDICO DA FASM}

De forma esquemática, o modelo educacional de MFC e APS no curso médico está desenhado conforme apresentado no Quadro 1.

Esse modelo foi inspirado nos modelos de aprendizagem significativa, em particular no descrito por Ausubel, em que conteúdos do conhecimento cognitivo se constroem de forma hierárquica pela superposição de conceitos mais amplos sobre conceitos menos amplos ${ }^{14}$. A partir da definição de conceitos fundamentais nas MFC 1 a 4, agregamos outros conceitos complementares e mais complexos, na forma de uma espiral ascendente de conhecimentos. Assim, tentamos criar um cenário propício para que o aluno desenvolva as competências relacionadas à área no final do curso médico.

\section{Objetivos educacionais}

A proposta curricular da FASM estabelece que no final do curso médico o aluno seja capaz de: realizar diagnóstico comunitário; realizar consulta utilizando o método clínico centrado na pessoa; realizar abordagem familiar utilizando tecnologias leves, tais como, genograma e ecomapa; trabalhar em equipe, conhecendo as atribuições dos profissionais e propondo articulações entre os núcleos de saberes; reconhecer as dificuldades enfrentadas pelos usuários no sistema de saúde e propor ações para mitigá-las; oferecer cuidado integral e humanístico, compreendendo o indivíduo no contexto de vida, familiar, social e ambiental.

Além disso, esperamos que o egresso compreenda o funcionamento do sistema de saúde, a articulação dos níveis de atenção primário, secundário e terciário, seja capaz de analisar situações-problema que afetem a eficiência do sistema e repercutam na qualidade do cuidado ofertado à população e seja capaz de elaborar soluções para estas situações.

\section{Conteúdo programático}

Conforme descrito no Quadro 1, o contato do aluno com o conteúdo da área ocorre em grau crescente de complexidade, conhecimentos, habilidades e atitudes, pela elaboração do contato de saberes prévios com novos saberes. A Figura 1descreve a temática central de cada módulo por semestre da graduação.

\section{Planejamento do processo educacional}

O planejamento de cada módulo é realizado em três etapas: (1) os docentes responsáveis pelo módulo constroem a proposta inicial considerando os objetivos pedagógicos e os temas a serem discutidos, e propõem as atividades a serem desenvolvidas em cada visita à UBS; (2) a proposta de cada módulo é apresentada e debatida por todos os docentes da MFC; (3) é realizado um fórum semestral de discussão com o propósito de articular conteúdos e práticas dos módulos da MFC com as disciplinas Epidemiologia, Bioestatística, Semiologia, Políticas Públicas, e Espiritualidade e Tanatologia.

As atividades nas UBS são planejadas de acordo com as competências a serem desenvolvidas em cada módulo de MFC. Mensalmente ocorre um encontro dos preceptores das UBS com os docentes da MFC. Os temas eleitos para discussão emergem de dois contextos: (1) dificuldades práticas vivenciadas pelos preceptores nas UBS e (2) temas propostos pelos docentes da FASM segundo o feedback dos alunos. Desse modo, criamos um espaço de elaboração, planejamento e avaliação das atividades teórico-práticas vinculadas à APS e à MFC, fundamentado na realidade local das UBS, nas dificuldades 


\begin{tabular}{|c|c|c|c|c|}
\hline \multicolumn{5}{|c|}{$\begin{array}{l}\text { QUADro } 1 \\
\text { Modelo educacional de MFC e APS do primeiro ao sexto ano do curso médico }\end{array}$} \\
\hline Bloco & Objetivo educacional & Conteúdo & $\begin{array}{l}\text { Metodologia didático- } \\
\text { pedagógica }\end{array}$ & Avaliação \\
\hline $\begin{array}{l}\text { 1. Sistemas de } \\
\text { Saúde, APS no } \\
\text { mundo e no } \\
\text { Brasil, trabalho } \\
\text { interdisciplinar, } \\
\text { o indivíduo, sua } \\
\text { família e seu } \\
\text { ambiente }\end{array}$ & $\begin{array}{l}\text { Conhecer princípios do } \\
\text { SUS e APS; } \\
\text { Identificar situações } \\
\text { que dificultam acesso, } \\
\text { longitudinalidade, } \\
\text { integralidade e } \\
\text { coordenação do cuidado; } \\
\text { Conhecer o trabalho } \\
\text { interdisciplinar na APS; } \\
\text { Identificar características } \\
\text { do contexto de vida das } \\
\text { pessoas relacionadas ao } \\
\text { processo saúde-doença; } \\
\text { Conhecer conceitos de risco } \\
\text { e vulnerabilidade. }\end{array}$ & $\begin{array}{l}\text { MFC } 1 \text { a 4; } \\
\text { O sistema de saúde } \\
\text { brasileiro; } \\
\text { APS no contexto mundial e } \\
\text { nacional; } \\
\text { Trabalho em equipe; } \\
\text { Abordagem familiar; } \\
\text { Diagnóstico comunitário; } \\
\text { Determinantes sociais do } \\
\text { processo saúde-doença. }\end{array}$ & $\begin{array}{l}\text { Aulas expositivas } \\
\text { dialogadas; } \\
\text { Team-based learning(TBL); } \\
\text { Role-playing; } \\
\text { Problematização. }\end{array}$ & $\begin{array}{l}\text { Portfólio; } \\
\text { Prova (questões } \\
\text { objetivas e } \\
\text { dissertativas); } \\
\text { Trabalhos em pequenos } \\
\text { grupos; } \\
\text { Discussão de artigos. }\end{array}$ \\
\hline 2. Clínico & $\begin{array}{l}\text { Conhecer conceitos de } \\
\text { saúde; } \\
\text { Conhecer ciclos de vida; } \\
\text { Desenvolver competência } \\
\text { para aplicar o método } \\
\text { clínico centrado na pessoa. }\end{array}$ & $\begin{array}{l}\text { MFC } 5 \text { a } 8 \text {; } \\
\text { Método clínico centrado na } \\
\text { pessoa, saúde da criança, } \\
\text { saúde do homem, saúde da } \\
\text { mulher e saúde do idoso; } \\
\text { Saúde sexual e reprodutiva; } \\
\text { Doenças mais prevalentes } \\
\text { em APS. }\end{array}$ & $\begin{array}{l}\text { Aulas expositivas } \\
\text { dialogadas; } \\
\text { Team-based learning(TBL); } \\
\text { Role-playing; } \\
\text { Problematização; } \\
\text { Osce (objective structured } \\
\text { examination). }\end{array}$ & $\begin{array}{l}\text { Portfólio; } \\
\text { Prova (questões } \\
\text { objetivas e } \\
\text { dissertativas); } \\
\text { Trabalhos em pequenos } \\
\text { grupos; } \\
\text { Osce. }\end{array}$ \\
\hline 3. Internato & $\begin{array}{l}\text { Desenvolver competências } \\
\text { clínicas para atendimento } \\
\text { integral e resolutivo, } \\
\text { identificando os papéis } \\
\text { dos contextos: família, } \\
\text { ambiente em que vive e } \\
\text { trabalho. }\end{array}$ & $\begin{array}{l}\text { MFC } 9 \text { a 12; } \\
\text { Doenças mais prevalentes } \\
\text { em APS; } \\
\text { Redes de Atenção à Saúde; } \\
\text { Coordenação do cuidado. }\end{array}$ & $\begin{array}{l}\text { Aulas expositivas } \\
\text { dialogadas; } \\
\text { Problematização; } \\
\text { Mini-Cex(mini clinical } \\
\text { evaluation exercise); } \\
\text { Osce. }\end{array}$ & $\begin{array}{l}\text { Osce; } \\
\text { Mini-Cex; } \\
\text { Portfólio; } \\
\text { Prova (questões } \\
\text { objetivas e } \\
\text { dissertativas). }\end{array}$ \\
\hline
\end{tabular}

enfrentadas pelos preceptores para garantir um ambiente adequado para que o processo educacional aconteça da melhor forma possível e nos objetivos educacionais e perspectivas do processo ensino-aprendizagem propostos pelo grupo de docentes. Além disso, é nesse espaço que discutimos e elaboramos estratégias para superar as dificuldades enfrentadas pelos preceptores, como reuniões com os gerentes, discussão das agendas e técnicas de discussão de casos, entre outras.

\section{Metodologias educacionais}

As seguintes estratégias didático-pedagógicas são utilizadas: aula expositiva dialogada, problematização, team based-learning, role-playing, julgamento simulado, seminários, Mini-Cex, Osce e trabalho em pequenos grupos (Quadro 1). A escolha do método fica a critério do docente e de sua familiaridade com as metodologias de ensino, desde que esteja de acordo com o objetivo educacional e com o conteúdo programático previsto.
Cabe ressaltar que os docentes de MFC são oriundos de equipes de saúde de família, além de terem sido preceptores de UBS antes de se tornarem docentes. Ter a experiência de trabalho na MFC e na APS fornece substrato aos docentes para elaborar os encontros com os alunos com base em situações-problema vivenciadas na prática, articulando o tema a ser discutido com a realidade prática. Tal fato não exime a necessidade de investir na formação didática do docente, desde a preparação de uma aula expositiva dialogada à elaboração e aplicação do Osce. Outro aspecto relevante foi destacado por vários estudos: o bom professor é um bom comunicador, empático e modelo atitudinal em qualquer contexto ${ }^{15}$. Tais características frequentemente estão presentes em professores de MFC, em particular pela vivência prática em seu campo de atuação.

O caso a seguir exemplifica uma atividade educacional elaborada para estudantes do oitavo semestre (Quadro 2). 
Figura 1

Módulos de Medicina de Família e Comunidade do primeiro ao décimo segundo semestre da graduação (Modelo Educacional MFC-FASM)

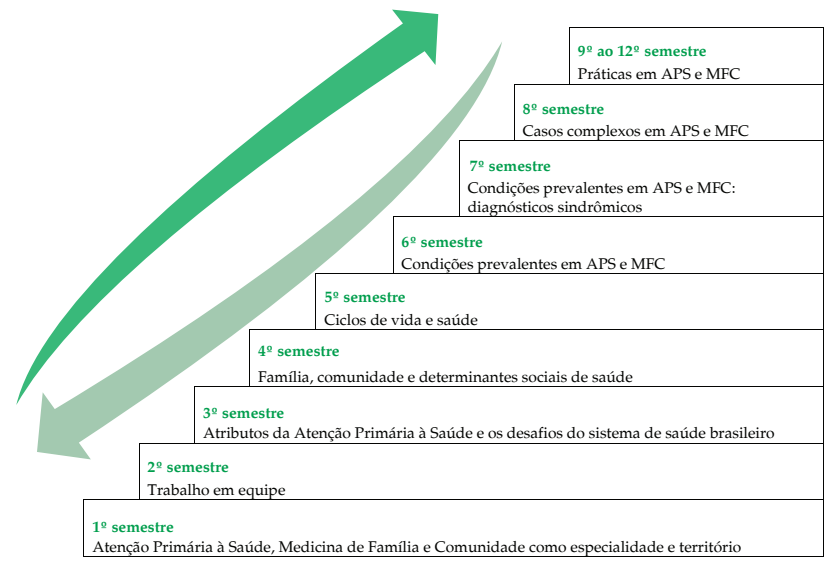

Tem como objetivo estimular o desenvolvimento de raciocínio clínico, crítico, ético e humanizado por meio da articulação de temas dos módulos de MFC do primeiro ao sétimo semestre e das disciplinas: Semiologia, Epidemiologia I e II, Trabalho em Equipe, Medicina Baseada em Evidência, Políticas Públicas de Saúde, Princípios do SUS e da APS, e Espiritualidade e Tanatologia. O caso é apresentado aos grupos de estudantes, e a discussão é desenvolvida em dois encontros.

\section{O processo de avaliação}

A avaliação dos estudantes é realizada de acordo com o postulado por Perrenoud ${ }^{16}$, considerando-se parte integrante do processo educacional e não restrita à mensuração de um processo vivido. Além de ser um modo de aferir o aproveitamento dos alunos, a avaliação é também um importante recurso pedagógico do processo educacional global. De acordo com a nossa proposta curricular, o processo avaliativo se caracteriza pela diversidade e pela combinação de métodos, com ênfase no caráter formativo. Optamos por processos avaliativos que incorporaram arranjos de triangulação de técnicas e instrumentos combinados, como provas teóricas, portfólios, Mini-Cex, Osce, autoavaliações e heteroavaliações ${ }^{17}$.

\section{GESTÃO EDUCACIONAL}

O desenvolvimento do processo educacional é determinado por sua gestão, que para MFC e APS também envolve ações organizativas dos processos de trabalho nas UBS. Destas ações destacam-se as descritas a seguir.

\section{QUADro 2}

Atividade educacional para estudantes do oitavo módulo de MFC

Cenário 1: Visita domiciliar da agente comunitária de saúde Márcia à Dona Cíntia

Márcia: Bom dia, Cíntia! Tudo bem com você?

Dona Cíntia: Oi, Marcinha! Então, tá quase tudo bem, só tem uma coisa comigo que só confio falar para você... é um "problema embaixo".

Márcia: Faz tempo que começou?

Dona Cíntia: Duas semanas. Até procurei o pronto-socorro(OS), e o doutor de lá passou uma pomada para coceira. Não deu tempo de examinar, tinha muita gente para ser atendida. Márcia: Cíntia, vamos fazer assim: vou conversar com a médica ou com a enfermeira da equipe e ver um horário para atender você ainda hoje.

\section{Cenário 2: Unidade Básica de Saúde}

Dra. Ana: Bom dia, Dona Cíntia. Tudo bem? A Márcia falou que a Sra. queria conversar comigo...

Dona Cíntia: Dra., tenho até vergonha de falar... mas é um "problema embaixo" e também queria um remédio para evitar filho. Tentei pegar no PS, mas o médico disse que a religião dele não permitia passar esse tipo de remédio...

\section{Segunda parte (Clínica e Epidemiologia)}

A partir das características da lesão: qual é a sua hipótese diagnóstica? (foto)

Descreva os possíveis estágios de progressão da doença, se não for tratada.

Que exames estão indicados para Dona Cíntia? Por quê?

Qual é o tratamento de escolha?

Que é a reação de Jarisch-Herxheimer? O que deve ser feito caso ocorra?

Que é aconselhamento? Quais profissionais da equipe devem realizar aconselhamento?

Comente os conceitos de risco e vulnerabilidade neste caso.

Há necessidade de preencher a ficha de notificação do Sistema de Notificação de Agravos de Notificação (SINAN)?

\section{Terceira parte (SUS, APS e ESF)}

A relação de confiança com a ACS Márcia foi imprescindível para garantir o cuidado integral. Que aspectos da APS e características da ESF contribuem para a construção do vínculo da população com a equipe?

Ao não examinar dona Cíntia e não orientar como poderia conseguir a medicação contraceptiva, quais princípios do SUS foram negligenciados pelo médico que a atendeu no PS? 
QuAdro 2

Atividade educacional para estudantes do oitavo módulo de MFC

\section{Quarta parte (Ética e Humanização)}

Considerando o Código de Ética Médica e os princípios da humanização, segundo a Política Nacional:

Avalie a conduta do médico do pronto-socorro;

Discuta como a assistência prestada no pronto-socorro poderia ser aprimorada.

(Prezado leitor, caso queira as respostas deste caso, envie e-mail para andreatenorio@usp.br)

1. Primeira parte (semiologia, genograma, lista de problemas)

Se você fosse a Dra. Ana, que perguntas faria à Dona Cíntia?

Com base nas informações abaixo, elabore o genograma e a lista de problemas individual e familiar.

Dona Cíntia (26 anos) queixa-se das brigas com o marido (Alberto), que reclama da falta de "sexo". Dona Cíntia diz estar cansada do trabalho (seis horas/dia numa empresa de telemarketing e ainda ter que cuidar dos três filhos - Jéssica, 3anos, Marcos, 6 anos, e Paula, 9 anos). Relata que realizou um aborto há dois anos porque seu marido "não queria mais um filho no mundo".

O Sr. Alberto tem duas irmãs mais velhas e um irmão caçula, de quem é muito próximo. Dona Cíntia é muito ligada à mãe $\mathrm{e}$ tem pouco contato com o pai, que abandonou a família quando ela tinha três anos. A mãe está em tratamento para depressão, o que deixa Dona Cíntia muito preocupada. Dona Cíntia tem um irmão mais novo do segundo casamento da sua mãe, com quem tem pouco contato, já que ele mora em outra cidade.

\section{Gestão e desenvolvimento de pessoas}

Dezoito preceptores e nove docentes de MFC estão envolvidos na elaboração e implantação do processo educacional. Entre eles estão os coordenadores do módulo básico, do módulo clínico, da articulação ensino-serviço e do internato em MFC. Cada grupo de quatro a cinco estudantes acompanha uma equipe de saúde da família. Atualmente, 18 equipes recebem os estudantes.

A seleção dos preceptores é um ponto-chave do processo educacional. Uma revisão da literatura sobre a experiência brasileira da preceptoria na APS aponta uma heterogeneidade dos médicos que assumem esse papel ${ }^{18}$. Nesse contexto, é necessário estabelecer critérios que favoreçam a seleção de preceptores com capacidade teórico-prática para a docência. Essa seleção é realizada de acordo com os seguintes critérios: tempo de atuação como MFC (pelo menos dois anos), título de especialista ou residência em MFC, experiência como preceptor e bom relacionamento com a equipe.

Os preceptores recebem uma bolsa da FASM de acordo com o número de estudantes acompanhados e a fase do curso, e desenvolvem diversas atividades vinculadas à faculdade. A ideia principal é promover a aproximação entre ensino e serviço, ampliar o pertencimento à equipe, ter suporte e construir propostas para lidar com as dificuldades. Assim, além da reunião mensal, que tem como objetivo debater os processos de ensino-aprendizagem com base na realidade local das UBS e discutir estratégias para enfrentá-la, os preceptores participam de oficinas sobre o processo ensino-aprendizagem e de workshops sobre técnicas de discussão de casos. Também atuam na construção e implementação de projetos acadêmicos da MFC da FASM - alguns são autores de vários capítulos do Manual do Médico de Família - FASM -, além de estar inseridos em projetos de pesquisa ligados ao Núcleo de Pesquisa em APS e MFC.

Algumas estratégias são utilizadas para aprimorar a comunicação entre os membros da equipe, como o uso do aplicativo Whatsapp, que permite explicar a atividade a ser desenvolvida na UBS em cada módulo da MFC a cada semana, possibilitando planejar as atividades realizadas na UBS articuladas aos temas discutidos no módulo de MFC do respectivo semestre e encaminhar textos via e-mail e via Whatsapp sobre temas ligados a MFC, medicina baseada em evidência, educação médica, entre outros.

\section{Articulação com o Hospital Santa Marcelina e com a Prefeitura}

A Organização Social responsável pela gestão das UBS da ESF nos bairros de Itaquera, Cidade Tiradentes, Guaianases, Itaim Paulista e São Miguel é a Casa de Saúde Santa Marcelina. Na coordenação da APS atuam dois médicos de família que também compõem o corpo docente da FASM. A articulação escola-serviço tem sido apontada na literatura como uma importante estratégia para a formação de recursos humanos para o SUS de acordo com a realidade das necessidades de saúde da população ${ }^{19}$. No caso em estudo, observa-se que essa articulação reduz a dicotomia entre o ambiente universitário e o contexto da gestão local, assim como o distanciamento entre quem planeja e quem executa as atividades de ensino. A presença de profissionais na construção teórica do ensino que também estão inseridos nos ambientes de atividades práticas minimiza as tensões entre esses dois cenários. Esses profissionais identificam potenciais preceptores e UBS com recursos adequados para receber os estudantes.

A construção dos campos de estágio segue as determinações da Secretaria Municipal de Saúde (SMS), inicialmente por 
meio de solicitação da FASM dos campos de estágio na APS. A SMS estabelece fluxos necessários à regulamentação oficial desses estágios e sua efetiva colaboração com o ensino e compromisso fundamental de melhoria da assistência prestada à população atendida. $\mathrm{O}$ contrato é renovado anualmente.

\section{DESAFIOS ENFRENTADOS}

As disciplinas de MFC e APS nos currículos médicos são experiências recentes que enfrentam desafios, desde desconhecimento e estranheza até desqualificação de seu campo de atuação na própria escola médica. Além disso, por sua natureza, dependem de serviços de saúde nem sempre adequados à atividade-fim e aos objetivos educacionais apresentados, como planta física e ambientes deteriorados do serviço de saúde, que não favorecem o cuidado e o ensino.

Atividades educacionais exigem procederes por vezes incompatíveis com as metas determinadas em documentos norteadores de gestão das unidades, o que torna desafiadora a legitimação dos profissionais que trabalham em UBS como preceptores e professores comum processo de trabalho que responda à demanda assistencial e à meta numérica de consultas mensais sem inviabilizar o ensino de qualidade. É necessário pactuar com as instâncias administrativas responsáveis pela gestão das unidades espaços protegidos em agendas do médico-preceptor, além de promover o reconhecimento profissional mediante contratação e remuneração pela instituição de ensino superior e formação pedagógica na lógica da educação permanente.

Vale ressaltar que, por ser um campo em desenvolvimento, há considerável falta de profissionais capacitados para o atendimento e ensino. Nas UBS faltam médicos e preceptores com formação adequada para sua atuação. Investir na preparação desses profissionais é fundamental para que sejam críticos e compromissados com o desafio de coadunar assistência e docência, processo que se sustenta pelo reconhecimento do seu trabalho e pela sensação de pertencimento ao grupo daqueles que conduzem o processo educativo, diminuindo a distância histórica e o preconceito segundo o qual a academia pensa e o serviço executa.

\section{FATORES FACILITADORES}

Na experiência aqui relatada, registramos aspectos facilitadores em grande parte responsáveis pelo êxito até aqui alcançado. A concepção de um curso médico que tenha como um dos fundamentos axiais a sólida formação em MFC e APS talvez seja o mais potente elemento aglutinador de esforços e resultados para seu ensino. Vontade política do aparelho formador é o ponto de partida singular desta experiência, que merece ser destacado. A história da instituição de assistência e ensino na área é outro fator de sucesso para a integração serviço-escola.

A proximidade entre a gestão local das UBS e os preceptores e gestores que também são docentes facilita a interlocução necessária às atividades didáticas. Investir na gestão da equipe de preceptores com alinhamento conceitual e metodológi$\mathrm{co}$, mantendo docentes e preceptores informados sobre cada atividade com o uso de diferentes tecnologias de comunicação, promove um estado de pertencimento e apoio constante entre todos que favorece a condução das atividades de ensino.

Uma política de recursos humanos que valorize e remunere melhor os preceptores também incentiva a adesão ao projeto educacional.

\section{DISCUSSÃO}

A formação médica tem sido alvo de discussão no mundo e no País diante das grandes mudanças na sociedade contemporânea e em suas demandas de saúde ${ }^{20}$. Transformações tecnológicas, sociais e epidemiológicas apresentam desafios à área da saúde, ao mesmo tempo em que a saúde, como um direito humano que deve ser assegurado pelo Estado, requer políticas públicas que respondam a esse compromisso. Nesse sentido, a APS é uma estratégia fundamental para a atenção à saúde em diversos países ${ }^{21}$, e o ensino de MFC, diretriz da formação médica ${ }^{5}$.

Entretanto, desenvolver médicos para responder às demandas oriundas de necessidades sociais fora das fronteiras do que traz prestígio e valor social ao médico e, mais ainda, tornar esta experiência atraente aos alunos de graduação para seguimento de sua formação nesta especialidade são árduas tarefas para as escolas médicas brasileiras .No Brasil, médicos são ajuizados pela especialidade que escolhem, segmento populacional que atendem, rendimento financeiro que obtêm de seu trabalho. Esses valores estão presentes na escola médica e determinam a escolha da especialidade, que é influenciada por esses valores e pelas ofertas do mercado de trabalho médico, que determinam condições e carga de trabalho, salário, reconhecimento e valorização social ${ }^{22,23}$.

Condições concretas de trabalho incluem espaços, distâncias, recursos tecnológicos. Na esfera pública, acrescentem-se as redes de serviços, que deveriam sustentar o modelo de atenção integral à saúde, princípio finalístico maior do SUS, em modelo de regulação do sistema que assume forma heterogênea e frequentemente insuficiente nas diversas regiões do País ${ }^{24}$.

A afirmação da MFC como especialidade atrativa na graduação que se efetiva na escolha da residência médica, respondendo à necessidade social de médicos para a APS, envol- 
ve, entre outros incentivos, carreira e salários atraentes, boa formação em MFC e APS, e oferta de adequado cenário de exercício profissional em rede de serviços em que o médico consiga desenvolver um trabalho de qualidade que garanta satisfação com a escolha profissional.

Dentro desta problemática e com foco na formação médica, relatamos aqui uma experiência de ensino que situa a MFC e a APS como áreas estratégicas no projeto pedagógico, com forte protagonismo institucional. O currículo do curso de Medicina da FASM definiu a MFC e a APS como eixos transversais de formação do primeiro ao último semestre, integrando temas, disciplinas, atividades, cenários de ensino e buscando a construção de um espaço institucional de legitimação desta área no panorama da educação médica. Isto já se observa no número de sujeitos que nela atua, entre docentes, preceptores, especialistas de outras áreas, na articulação com outras disciplinas e unidades de serviço, e na criação de um núcleo de pesquisa voltado à MFC e à APS. A organização de seminários de integração interdisciplinar com as disciplinas do ciclo básico e profissional em que a MFC atua como disciplina aglutinadora e a produção coletiva de um livro sobre a prática nesse campo são exemplos de sua capacidade integrativa e criativa dentro do currículo.

Entre as medidas adotadas com vistas à excelência do ensino, destacam-se: (1) inserção dos alunos em UBS com Estratégia Saúde da Família (ESF) e nos equipamentos do território de cada equipe do primeiro ao oitavo semestre, bem como no internato médico, para o desenvolvimento de competências na realização de anamnese e exame físico, formulação de hipóteses diagnósticas e elaboração de projetos terapêuticos adequados à realidade local; (2) contratação de médicos de família para atuação como docentes da faculdade; (3) construção de ações interdisciplinares com epidemiologia, políticas de saúde, espiritualidade e medicina baseada em evidências; (4) utilização de metodologias problematizadoras no processo de ensino, adequadas à temática abordada, ao perfil do estudante e à expertise do docente; (5) utilização de avaliações preferencialmente formativas, com diversidade de estratégias avaliativas como recurso para o desenvolvimento de competências esperadas para cada fase do discente; (6) aprimoramento pedagógico-assistencial dos docentes e dos preceptores por meio de educação permanente com foco no desenvolvimento das competências para o exercício do ensino em saúde; (7) discussão de temas como processo saúde-doença, território, atributos essenciais e derivados da APS, abordagem individual e familiar e comunitária, o médico de família no Brasil e no mundo, método clínico centrado na pessoa, medicina baseada em evidência, medicina narrativa, manejo de problemas mais prevalentes, coordenação do cuidado, atuação com foco na integralidade, desenvolvimento dos conhecimentos, habilidades e atitudes necessários a uma prática segura e resolutiva, entendimento do ambiente domiciliar como setting terapêutico para a prática clínica integral, elaboração de histórias de acordo com o registro clínico centrado na pessoa e garantindo registro seguro, incentivo a práticas que sensibilizem o aluno para o trabalho em equipe e ações interprofissionais, estudo de mecanismos de avaliação da qualidade dos processos de trabalho da APS; (8) incentivo a programas de intercâmbio nacionais e internacionais com programas de graduação e residência em MFC, para aprimoramento e troca de experiências; (9) fomento à publicação de livros, artigos e pesquisa na APS, elaborados por docentes, preceptores e discentes.

Os esforços resultaram, para os preceptores, em sensação de pertencimento ao grupo docente e estímulo para se fixarem nas UBS. Em três anos de graduação, a rotatividade entre preceptores é inferior a 15\%, enquanto para o restante de médicos da rede local é de cerca de $40 \%$ ao ano. Uma vez que se sentem estimulados a continuar em seus postos de trabalho, coadunando as funções de médicos da assistência e docência, ocorre a qualificação dos processos de gestão do acesso, de integralidade, longitudinalidade e coordenação do cuidado, pressupostos nucleares da APS ${ }^{25}$.

O conjunto de conceitos, métodos e experiências em desenvolvimento no currículo da graduação em Medicina da FASM, com destaque para MFC e APS, pode trazer elementos para o debate atual sobre o engajamento da formação médica nas questões de saúde na contemporaneidade, tendo o firme propósito de colaborar com a qualificação do SUS e da APS na construção de um país mais equânime e socialmente justo no campo da saúde como direito humano.

\section{REFERÊNCIAS}

1. Paim J, Travassos C, Almeida C, Bahia L, Macinko J. The Brazilian health system: history, advances, and challenges. Lancet 2011;377:1778-97.

2. Schmidt MI, Duncan BB, Silva GA, Menezes AM, Monteiro CA, Barreto SM et al. Chronic non-communicable diseases in Brazil: Burden and current challenges. Lancet 2011;377:1949-1961.

3. Brasil. Minitério da Educação. Diretrizes curriculares nacionais do curso de graduação em medicina 2001.[acesso em 12 abr 2016] Disponível em: http:/ / portal.mec.gov.br/ cne/arquivos/pdf/CES04.pdf.

4. Brasil. Ministério da Saúde. Projeto de Incentivo a Mudanças Curriculares nas Escolas de Medicina. [acesso em 23 jul 2016] Disponível em: http://portal.mec.gov.br/sesu/ arquivos/pdf/inc.pdf. 
5. Brasil. Minitério da Educação. Diretrizes curriculares nacionais do curso de graduação em medicina 2014.[acesso em 9 jan 2016] Disponível em: http://portal.mec.gov.br/index. php?option=com_docman\&view=download\&alias $=15874$ -rces003-14\&Itemid=30192.

6. Demarzo MMP, Almeida RCC, Marins JJN, Trindade TG, Anderson MIP, Stein AT et al. Diretrizes para o ensino na atenção primária à saúde na graduação em medicina. Rev Bras Educ Med 2012;36:143-148.

7. Conselho Federal de Medicina (Brasil). Radiografia das Escolas Médicas no Brasil. [acesso em 19 jan 2016] Disponível em: http://webpainel.cfm.org.br/QvAJAXZfc/opendoc.htm?document=Radiografia do Ensino $\mathrm{m} \% \mathrm{C} 3 \%$ A9dico $\% 2 F$ Radiografia doEnsino m\%C3\%A9dico. qvw\&host=QVS\%40scfm73\&anonymous=true.

8. Pagliosa FL, Ros MA. O relatório Flexner: para o bem e para o mal. Rev Bras Educ Med 2008;32:492-499.

9. Oliveira NA, Meirelles RMS, Cury GC, Alves LA. Mudanças Curriculares no Ensino Médico Brasileiro: um Debate Crucial no Contexto do Promed. Rev Bras Educ Med 2008;32:333-346.

10. Vieira JE, Elias PEM, Benseñor IJM, Grisi SJE. Instalação da disciplina de Atenção Básica em Saúde na Faculdade de Medicina da Universidade de São Paulo (2003-2006). Rev Bras Educ Med 2007;31:236-244.

11. Carvalho SR, Garcia RA, Rocha DC. O ensino da Saúde Coletiva no curso médico da Unicamp: experiências inovadoras junto a unidades básicas de saúde. Interface 2006;10: 457-472.

12. Brandão ERM, Rocha SV, Silva SS. Práticas de Integração Ensino-Serviço-Comunidade: Reorientando a Formação Médica. Rev Bras Educ Med 2013;37:573-577.

13. Alves HF. Vulnerabilidade socioambiental na metrópole paulistana: uma análise sociodemográfica das situações de sobreposição espacial de problemas e riscos sociais e ambientais. Rev Bras Est Pop 2006;23:43-59.

14. Ronca ACC. Teorias de ensino: a contribuição de David Ausubel. Temas em Psicol 1994;2: 91-95.

15. Costa NMD, Cardoso CG, Costa DC. Concepções sobre o bom professor de medicina. Rev Bras Educ Med 2012;36:499-505.

16. Perrenoud P. Avaliação: da excelência a regulação da aprendizagem entre as lógicas. 2ed. São Paulo: Artes Médicas;1999.

17. Macedo RS. Currículo, diversidade e equidade: luzes para uma educação intercrítica.1.ed. Salvador: EDUFBA; 2007.

18. Autonomo FROM, Hortale VA, Santos GB, Botti SHO. A Preceptoria na Formação Médica e Multiprofissional com
Ênfase na Atenção Primária - Análise das Publicações Braisleiras. Rev Bras Educ Med 2015;39: 316-327.

19. Pizzinato A, Gustavo AS, Santos BRL, Ojeda BS, Ferreira E, Thiesen FV et al. A Integração Ensino-Serviço como Estratégia na Formação Profissional para o SUS. Rev Bras Educ Med 2012;36:170-177.

20. Rios IC. Subjetividade contemporânea na educação médica: a formação humanística em medicina. São Paulo. Tese [Doutorado em Ciências] - Universidade de São Paulo; 2010.

21. Organização Mundial da Saúde. Primary Health Care: now more than ever. Geneva: WHO; 2008.

22. Cruz JAS, Sandy NS, Vannuchi TR, Gouveia EM, Passerotti CC, Bruschini H, Srougi M. Fatores determinantes para a escolha da especialidade médica no Brasil. Rev Med (São Paulo 2010;89(1):32-42.

23. Lefevre JH, Roupret M, Kerneis S, Karila L. Career choices of medical students: a national survey of 1780 students. Med Educ 2010;44:603-612.

24. Mendes EV. 25 anos do Sistema Único de Saúde: resultados e desafios. Estud Avançados 2013;27(78):27-34.

25. Starfield B. Is primary care essential? Lancet 1994;344:11291133.

\section{CONTRIBUIÇÃO DOS AUTORES}

Andréa Tenório Correia da Silva: concepção do manuscrito, escrita do texto principal, análise e discussão dos dados e revisão do texto. Martim Elviro de Medeiros Junior: elaboração do texto principal, análise e discussão dos achados. Paulo de Nogueira Fontão: elaboração do texto principal e revisão. Haraldo Cesar Saletti Filho: elaboração do texto principal e revisão. Pedro Félix Vital Junior: elaboração do texto principal e análise dos dados. Monique Marie Marthe Bourget: elaboração do texto principal e revisão. Izabel Cristina Rios: concepção do manuscrito, escrita do texto principal e revisão final.

\section{CONFLITO DE INTERESSES}

Não há conflito de interesses

\section{ENDEREÇO PARA CORRESPONDÊNCIA}

Andréa Tenório Correia da Silva

Faculdade Santa Marcelina - Medicina de Família e Comunidade

Rua Cachoeira Utupanema, 40

Itaquera -São Paulo

CEP08270-140-SP

E-mail: andreatenorio@usp.br 